\title{
On the Flip Side of the Coin: Thinking Dispositions in Learning Blogs
}

\author{
Kurtz Gila*, Peleg Ela \\ School of Education, The College for Academic Studies, Or-Yehuda, Israel \\ *Corresponding author: kurtzgila@gmail.com
}

Received October 08, 2014; Revised December 26, 2014; Accepted January 05, 2015

\begin{abstract}
This paper describes a study of a blog, a web 2.0 application, as a learning tool for promoting thinking dispositions. The study was conducted at the College for Academic Studies in Israel, in the Master Program of ICT and Learning. Data was collected from a sample of students' blogs using rubric for the study. The results show that students' postings displayed evidence of thinking dispositions processes. In almost all blogs there were indications of a variety of thinking dispositions In addition, the findings indicate an increase in frequency of 2.3 representations of habits of mind during the period of this study.
\end{abstract}

Keywords: learning blog, thinking dispositions, development, quality thinking

Cite This Article: Kurtz Gila, and Peleg Ela, "On the Flip Side of the Coin: Thinking Dispositions in Learning Blogs." American Journal of Educational Research, vol. 3, no. 1 (2015): 16-19. doi: 10.12691/education-3-1-4.

\section{Introduction}

A blog (derived from the earlier term, web log) is an internet site where people write entries, or "posts" about experiences, news, and articles. The content of the posts is accessible to internet surfers, who can read them and, in most cases, react to them as well [5,9]. Pang, 2009). A learning blog, also known as an e-portfolio, is a collection of textual and/or multimedia web pages that includes resources, demonstrations, and educational activities that represent the student that posts them and his or her learning process.

Most blogs share three common characteristics:

1. Reverse-order chronological presentation of the narrative - the present is constantly emphasized, with past milestones appearing only later.

2. The content refers to current issues in the consciousness of the writer.

3. Updated posts appear regularly.

Blogs are not restricted by the physical limitations of pages and sheets of paper, and are not subject to editing instructions or other formal constraints. The content of the post is brief and usually focused on a single issue, presented in the format of ad hoc communication. The writing style is informal, consisting of short sentences with no distinction according to the nature of the content, be it technical, journalistic, or a description of a personal experience [6] Hourihan, 2002).

Blogs are an appealing means of learning, because of their ease of use and the possibility of adding content without knowing programming languages. As a simple-touse application that is accessible and direct, the blog has become a very powerful instrument, capable of supporting personal and group learning. The ability to integrate a variety of multimedia applications and hyperlinks empowers the blog's contribution to the development of wide-ranging knowledge and cognitive processes [2,4,12].

In her doctoral thesis, Diane Hall [3]. listed four main advantages of learning blogs:

1. They help students be experts in the relevant field of study.

2. They increase motivation in the learning process.

3. They offer an innovative, interactive channel for participation in the learning process.

4. They provide a forum for diverse opinions and attitudes within and outside of the classroom.

Learning blogs offer students a voice in their own personal technological space [5]. They provide a technological platform for examining how the formal theoretical knowledge taught in class and the reading materials interrelate with the student's practical experience [7]. In addition, the public nature of the writing increases the student's sense of responsibility for the learning process [5].

Research conducted by the US Department of Education revealed that computer-assisted learning, and particularly learning blogs enrich the learning process, among other reasons because they enable students to channel the processes of interaction with the environment at their convenience and they encourage reflective processes, which promote improved learning outcomes [11].

A salient concept in the present research is TD Thinking Dispositions, which is broadly defined as tendencies toward particular patterns of intellectual behaviour. Perkins, Jay, and Tishman [13], advance a view of seven key critical thinking dispositions. Building on their triadic conception of disposition, they argue that 
each of these seven tendencies involve distinct sensitivities, inclinations, and abilities. The seven dispositions are:

1. The disposition to be broad and adventurous

2. The disposition toward wondering, problem finding, and investigating

3. The disposition to build explanations and understandings

4. The disposition to make plans and be strategic

5. The disposition to be intellectually careful

6 . The disposition to seek and evaluate reasons

7. The disposition to be metacognitive

\section{The Research Aim}

The purpose of this research was to examine whether the blog environment fosters and promotes the utilization of TD. In examining the degree to which blogs contain evidence of thinking actions that characterize TD. The content analysis category was based on a rubric developed by the researchers, for the purposes of this study. The rubric was used as a basis for coding TD and their components in the learning blogs records.

\section{The Research Population Instrument}

The research population consisted of 25 master's degree students of education enrolled in a specialization track on computers and learning, who wrote weekly blogs throughout the course of an academic year (2010-2012). Writing the blogs was intended to be an integrative application of the courses that would create a professional identity and describe the student's learning process, experiences, and insights.

We conducted a quantitative content analysis of a sample of 25 learning blog posts students, with the purpose of identifying and characterizing TD. Systematic random sampling was used to select the posts and the coding and categorization were subjected to an inter-judge reliability test, as accepted.

\section{Finding}

\subsection{Research Question 1: To what Extent is it Possible to Detect Incidences of TD} Representations the in the Learning Blogs?

The quantitative content analysis indicated that representations of TD were found in all the blogs.

The prominent TD in the records were: the disposition to be broad and adventurous, for instance: "as soon as the students used their strengths, in their own playground, they felt safe, they had a clear goal, an immediate feedback...all these encouraged them to come up with convincing arguments, to present [them] in an original and convincing way" (Blog 11); and also the disposition to be metacognitive, for instance: "when I write a post... I think of things I studied and notice the things that make me keep thinking, re-examining..." (Blog 24).
Based on the findings, it can be concluded that writing a learning blog promotes significant utilization, in numerical terms, of TD. (see Figure 1).

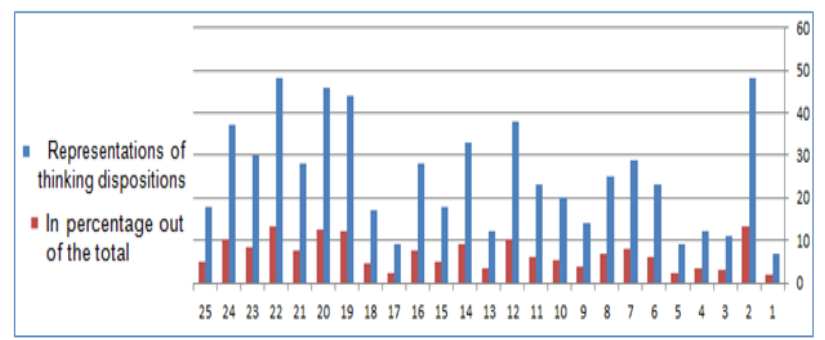

Figure 1. Representations of TD According to Blog

\subsection{Research Question 2: To what Extent do the Learning Blogs Contain Representations of a Variety of TD?}

As shown in Figure 2, in most of the blogs a variety of TD were utilized. Furthermore, in $94 \%$ of the posts, the students used at least one thinking disposition, while the average TD in these posts was 6.6 TD per post.

In more than $50 \%$ of the posts, at least 5 representations of TD were found.

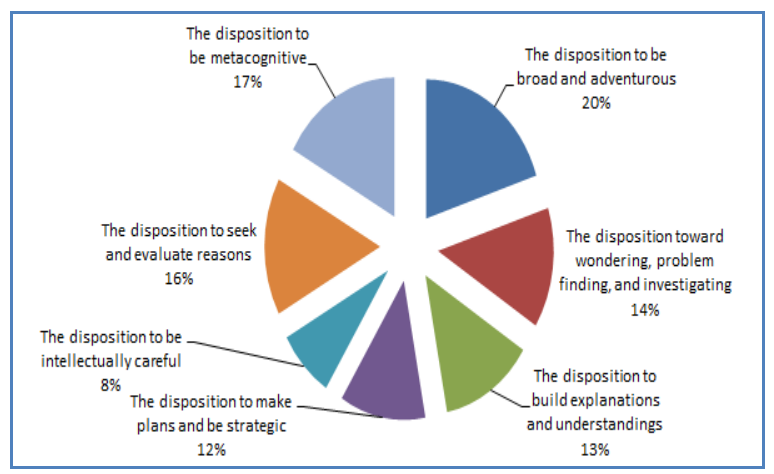

Figure 2. Variety of Representations of TD in a Single Record

In one of the posts which included the whole variety of thinking dispositions, the student wrote: "each post written by me every week was carefully planned and phrased accordingly. The wording was chosen after filtering and was frequently modified...the gradual critical thinking processes I went through and the feedback came up especially during the nights..." (An example of the disposition to be metacognitive representation). As well as, "the posts were written letter by letter, and they got their 'first sign of life' by reactions which served as a feedback for the log. Hurrah, someone read it!" (An example for the representation of the disposition to explanations and understandings).

According to the findings, as illustrated in Figure 2, it can be concluded that writing a learning blog provides an opportunity for the representation of a variety of TD.

\subsection{Research Question 3: To what Extent is it Possible to Detect Development in the Scope of TD in the Course of Writing the Learning Blog?}

In order to answer this question, we examined the blogs in their first period and in their final phase of writing. In 
the examination of the incidences of TD in the course of writing, the results showed an increase of 2.3 in the incidences of TD representations at the final phase of writing the blog, in comparison to the initial phase (see Figure 3). It indicates that the students used less TD in their early posts, with an upward trend in the representation of TD along the time axis. Thus, the findings reveal a positive development in the scope of use of TD in the learning blogs. Which suggested that the learning blog encourages and contributes to an accurate and thorough thinking activity, independent inquiry, flexible and creative thinking and reflection processes which improve the quality of thinking and the products of learning.

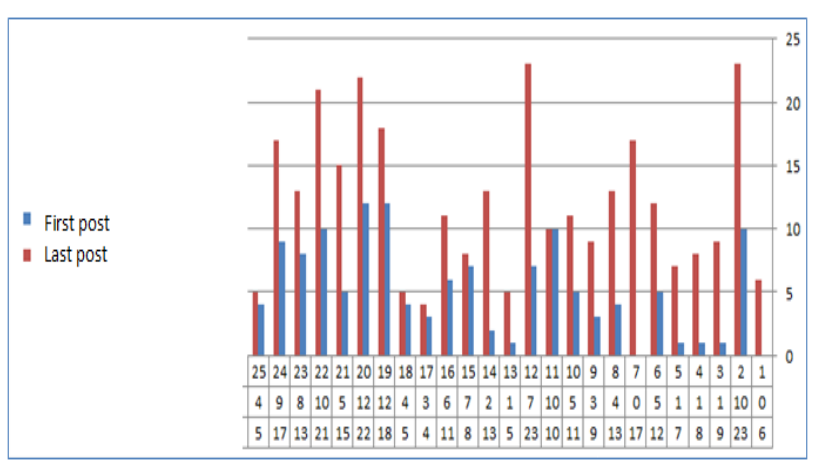

Figure 3. Incidence of TD- First and Last Record

\section{Discussion and Conclusions}

The present research examined the utilization of TD in blogs from a broad, process-oriented perspective of the blog throughout a period of writing of 18 months, the use of variety of TD and the possibility of an increase in the incidence of use of thinking dispositions.

In order to answer the first research question - "To what extent is it possible to detect incidences of TD representations the in the learning blogs? We examined whether TD are indicated in the learning blog. The examination of the blogs and the sample posts clearly indicated representations of TD in all the blogs. Finding evidence for TD in blogs such as the disposition to be metacognitive, and other dispositions, imply the development of critical thinking patterns, which contribute to a significant learning and for building a new knowledge [8], as well as that the new setting encourages the creation of new thinking functions [1]

The second research question - "To what extent do the learning blogs contain representations of a variety of TD?" - examined the extent to which the students utilized a wide range of TD. It was found that almost in all the blogs a use of a variety of TD was made. More than that, in 94\% of the records the students used at least one thinking disposition while the average number of TD used in these records was 6.6 TD per record. In more than $50 \%$ of the records, at least 5 representation of TD were found. The meaning of this result is that during the writing of the records in the learning blog, the students used a variety of thinking dispositions, significantly.

Thus it can be concluded that the active writing in the learning blog led to the expansion of the variety of use of thinking dispositions. In addition, it was found that the disposition to be broad and adventurous was the most common disposition. This result may suggest that the activity in the learning blog offers independent selflearning which necessitates open mindedness, attentiveness for narrow-mindedness, thinking of many possibilities and brain storming with peers. The results regarding the use of a variety of TD may suggest that the activity in the learning blog influences the dispositions and skills of the students in different directions: among other things, it completes or extends the dispositions [1].

The third research question was: "To what extent is it possible to detect development in the scope of TD in the course of writing a learning blog?" In other words, we sought to determine whether weekly blogging for a long period led to greater utilization of TD by the students with every post. The findings indicated an upward trend in the scope of utilization. The results present an extension of use of all seven measures of TD an increase of 2.3 fold in the incidence of TD representations at the final phase of writing the blog, in comparison to the initial phase. This suggests that the act of blogging, the weekly experience, and response from readers led to increased utilization of $\mathrm{TD}$, as reflected in the posts.

\section{Summary}

The present empirical pioneer study was designed to examine the existence and increase in incidence of higher education student's TD in their activity in a learning blog. The research findings revealed that the learning blog contains representations of TD, in both large quantity and wide variety. In addition, a developmental process in the extent of TD representations can be traced in the learning activity. The blog can serve for an accurate and thorough mental activity, independent inquiry, flexible and creative thinking and its use encourages reflection. The results of the present study and those found in the study of Kurtz and Porath [10] suggest that the learning blogs are indicative of a development of a qualitative thinking and thus can serve as a mean to promote the achievement of this goal.

\section{Limitations of the Research and Recommendations for Further Research}

This study has certain limitations that should be considered for further research. The small sample of the current study limits its generalizability to the entire world of learning blogs. Readers may need to interpret the results carefully because this study is context specific and involves a limited research questions. It is clear that the authors do not intend to generalize these results to a wider population or context. It is vital to extend this type of research to include representative groups of learners who differ in their phase of study, individual characteristics, and learning content. More studies are required, in different learning contexts and among other learners' populations, in order to validate its results.

Finally, it is hoped that this research will provide a basis for further research and will provoke and encourage new thinking and new practices in the educational field with the use of web 2.0. applications such a learning blog. 


\section{References}

[1] Ben-Ami, Y. \& Chen, D. (2011) Digital knowledge technologies broadening the existing cognitive abilities or a qualitative cognitive change? In: Online learning and teaching (eds. D. Chen \& G. Kurtz), Or-Yehuda: The College for Academic Studies (Hebrew).

[2] Bloom, B.S. (ed.) (1956). Taxonomy of educational objective: The classification of educational goals. New York: David Mckay Company.

[3] Diane Hall, K. (2008). Discussion forum versus learning blogs: A comparison of student understanding, student interaction, and social presence, A Dissertation. March 3, 2011. http://etd.lib.ttu.edu/theses/available/etd-10302008-

125439/unrestricted/Hall_Kimberly_Diss.pdf

[4] Downes, S. (2004), Educational Blogging. EDUCAUSE Review, vol. 39, no. 5. March 21, 2011. http://www.educause.edu/EDUCAUSE+Review/EDUCAUSERev iewMagazineVolume39/EducationalBlogging/157920

[5] Ellison, N. B., \& Wu, Y. (2008). Blogging in the classroom: A preliminary exploration of student attitudes and impact on comprehension. Journal of Educational Multimedia and Hypermedia. 17 (1), (pp. 99-122).

[6] Forster, P. W. \& Tam, T. (2004). Blogging in an MBA Classroom: Personal Experiences, Department of Information System Management, The Hong Kong University of Science and Technology. March

21 ,

2011. http://repository.ust.hk/dspace/bitstream/1783.1/1728/1/pl01 forst er_ismt_paper.pdf

[7] Gray, L. (2008). Effective Practice with e-Portfolios. September 1, 2011 www.jisc.ac.uk/eportfolio

[8] Kurtz, G. (2011) Implementing ICT technologies: Challenges and promises. In Online learning and teaching (eds. D. Chen \& G. Kurtz), Or-Yehuda: The College for Academic Studies (Hebrew).

[9] Kurtz, G. \& Chen, D. (2012). ICT for learning: A toolkit for teachers. Or-Yehuda: The College for Academic Studies (Hebrew).

[10] Kurtz, G. \& Porath. N. (2012). Higher order thinking strategies in learning blogs. A paper presented at the EDEN conference. Porto, Portugal.

[11] Means, B., Toyama, Y., Murphy, R., Bakia, M. and Jones, K. (2009). Evaluation of Evidence-Based Practices in Online Learning: A Meta-Analysis and Review of Online Learning Studies. U.S. Department of Education. September 21, 2009, from http://www.gilfuseducationgroup.com/wpcontent/uploads/2009/09/Evidence-Based-Practices-in-OnlineLearning-Review-of-Online-Learning-Studies.pdf

[12] Minocha, S. \& Kerawalla, L. (2011). University Students' SelfMotivated Blogging and Development of Study Skills and Research Skills. In Lee, M.J.W \& Mcloughlin, C. (Ed.), Web $2.0-$ based e-learning: Applying social informatics for teaching tertiary. Chapter 8 (pp. 149-179). New York: Information Science Reference .

[13] Perkins, D.N., (2009). Making Learning Whole: How Seven Principles of Teaching Can Transform Education, Jossey-Bass, San Francisco. 